\title{
GENETICAL AND ENVIRONMENTAL VARIATION FOR RESISTANCE TO BACTERIAL BLIGHT OF UPLAND COTTON
}

\author{
N. L. INNES,* and S. J. BROWN $\dagger$ \\ Cotton Research Corporation, Cotton Research Station, Namulonge, Kampala, Uganda \\ and \\ J. T. WALKER
}

Rothwell Research Station, Rothwell, Lincoln, England

Received 19.j.73

\section{SummaRY}

\begin{abstract}
The inheritance of resistance in Upland cotton to Xanthomonas malvacearum was investigated using a half diallel set of crosses between six inbred varieties. Parents and progeny were inoculated and examined at three sites: Shambat and Wad Medani in the Sudan, and Namulonge in Uganda. In the Sudan, leaves only were inoculated. At Namulonge leaves and bolls were inoculated and two bacterial cultures were used on the latter organs.

Diallel analyses based on those developed by Hayman, Jinks and Allard were computed. Special note was taken of non-additive genetic relationships. Dominance was found to account for non-additivity, and the data were examined for interactions involving sites and bacterial cultures. The behaviour of the $B_{7}$ gene was not consistent with its being a simple Mendelian locus with incomplete dominance. Genetic variances varied with inoculum, being lower with culture NCG 40 than with NCG 38 . Line $4,101-102 B$, contains a polygenic complex in addition to genes $B_{2}$ and $B_{3}$. It has outstanding resistance and could be invaluable breeding material. Progeny of 101-102B demonstrate that resistance built up by selection of minor genes can be effectively transferred.
\end{abstract}

\section{Introduction}

THE inheritance of resistance of the cotton plant to bacterial blight (Xanthomonas malvacearum (E. F. Sm.) Dowson), was first demonstrated by Knight and Clouston (1939). Knight and his collaborators at Shambat in the Sudan developed techniques for inoculation and scoring disease severity. They then screened wild and cultivated cottons for genetical resistance and located the " $B$ " series of genes. In early work deviations from Mendelian ratios were ascribed to "modifiers", to genetical disturbance from interspecific crosses and to environmental variation.

Breeders then concentrated on transferring $B$ genes to commercial varieties by backcrossing. This was straightforward when using $B$ genes from the tetraploid $(4 n=52)$ species, Gossypium barbadense and G. hirsutum, that produce the modern cotton crops. Transference to these species from various diploids $(2 n=26)$ was more difficult, usually necessitating autotetraploid synthesis, as in the case of $B_{9 K}$ from $G$. herbaceum (Knight, 1963).

The expression of resistance varies with genetical background: $B_{9 \mathrm{~K}}$ for instance, is more effective in $G$. barbadense than in $G$. hirsutum whereas the opposite is true of the weaker $B_{11}$ (Innes, 1966). Knight recognised the

* Present address: National Vegetable Research Station, Wellesbourne, Warwickshire.

$\dagger$ Present address: Plant Breeding Institute, Cambridge. 
complicating effects of " minor genes" with variable expression, and found that some interacted with resistance genes at other loci. $B_{6}$, for example, intensified others and was thus often termed $B_{6 m}$ ( $m$ for modifier) (Knight, 1957). It was eventually shown to be recessive (Saunders and Innes, 1963). A further complication was the discovery of genetical variation for virulence in the pathogen (Brinkerhoff, 1963).

Recent work on bacterial blight has concentrated on interactions of genotypes with environment and upon the build-up of genetical resistance by selection of polygenes in populations exposed to the disease (Arnold, 1963; Arnold and Brown, 1968).

In this study two sites in the Sudan were used: Shambat, near Khartoum, is only $177 \mathrm{~km}$ from Wad Medani, but the two environments are quite different ecologically. Knight's (1957) data were obtained at Shambat, but between 1963 and 1965 the breeding material was moved south to Wad Medani in the Gezira (Innes, 1970).

The inheritance of resistance to blight in a half diallel set of crosses of five inbred Upland ( $G$. hirsutum) varieties screened at Namulonge (Uganda) and Wad Medani was described by Innes and Brown (1969). They found that additive and dominance components accounted for most of the genetical variance in their experiments. Three parents from their study and three other inbreds were used in the present work; Shambat was added as a third location.

In the following account Hayman's (1954a) analysis of variance was used for preliminary screening before applying the $W r / V r$ graphical method of Jinks (1954) and Hayman (1954b). Sites were too few to allow useful analysis by other regression methods, but Allard's (1956a) method of evaluating the stability of additive, dominance and non-allelic interaction variances was used.

\section{Materials and methods}

The six inbred lines used, with their $B$ gene content (Knight, 1957; Bird and Hadley, 1958; Joham, Lipke and Hold, 1967) were:

\begin{tabular}{lccc}
\multicolumn{1}{c}{ Genotype } & Code & $B$ genes & Origin \\
Acala 4.42 & 1 & $b$ & U.S.A. \\
Bar 7/1 & 2 & $B_{2} B_{2}$ & Sudan \\
Bar 24/5 & 3 & $B_{7} B_{7}{ }^{*}$ & Sudan \\
101-102B & 4 & $B_{2} B_{2} B_{3} B_{3} B_{S_{m}} B_{S_{m}} \dagger$ & U.S.A. \\
Acala 1517BR & 5 & $B_{7} B_{7}{ }^{*}$ & U.S.A. \\
Bar 12/16 & 6 & $B_{2} B_{2} B_{6} B_{6}$ & Sudan
\end{tabular}

At each site six parents and the $15 \mathrm{~F}_{1}$ 's and $15 \mathrm{~F}_{2}$ 's comprising the half diallel set were grown in a $6 \times 6$ triple lattice, with three replicates (blocks). Reciprocal crosses were not used, as tests have so far failed to indicate maternal effects upon blight resistance. At the Sudan sites there were three plants per hill at $80 \mathrm{~cm} \times 50 \mathrm{~cm}$ (66 plants per plot); at Namulonge there was one plant per hill at $90 \mathrm{~cm} \times 60 \mathrm{~cm}$ (40 plants per plot). Leaves and

* $B_{7}$ denotes resistance from the Upland variety Stoneville 20. In Bar 24/5, it was transferred to Acala 4.42 via G. barbadense (Innes, 1964); in Acala 1517BR the transfer was direct (Blank and Hunter, 1955).

$\dagger B_{S m}$ is the Stoneville minor gene complex. 
bolls were inoculated at Namulonge and leaves only in the Sudan, using techniques described by Innes and Brown (1969). Inoculation and scoring dates are given in table 1.

On the third occasion of boll inoculation at Namulonge plots were split

TABLE 1

Inoculation and scoring dates

$\begin{array}{lcr}\text { Leaf } & \text { Inoculation } & \text { Scoring } \\ \text { Namulonge } & & \\ \text { Wad Medani } & 21-23.8 .67 & 16-20.9 .67 \\ \text { Shambat } & 26-27.8 .67 & 16-17.9 .67 \\ & 28-29.8 .67 & 13.9 .67 \\ \text { Boll } & & \\ \text { Occasion 1, Namulonge } & 16.10 .67 & 6.11 .67 \\ \text { Occasion 2, Namulonge } & 23.10 .67 & 13.11 .67 \\ \text { Occasion 3, Namulonge } & 30.10 .67 & 23.11 .67\end{array}$

for two bacterial cultures, NGG 38 and NGG 40. Arnold and Brown (1968) had shown that both cultures were on average highly virulent, but plants showed different reactions to each culture in different environments. Also, on average, the intra-population variance for host resistance was less for NGG 38 than for NCG 40.

Computer analyses of single occasions and cultures, were made at Birmingham University using a FORTRAN programme by M. J. Lawrence. Some pooled analyses were also performed in Birmingham, but most of these, including all data matrices from which arrays were omitted, were evaluated in Edinburgh. The programme was the diallel facility in ASCOP, originated by B. E. Cooper and extended with the help of M. H. Moores.

For Hayman analyses of variance Bartlett's test for heterogeneity was made on interaction variances $B a, B b_{1}, B b_{2}$ and $B b_{3}$ prior to extracting site effects. When these variances were homogeneous components were tested against the common error $\left(B_{t}\right)$ : when they were heterogeneous each main item was tested against its appropriate interaction.

\section{Results AND Discussion}

\section{(a) Distribution patterns of leaf disease grades}

Frequency histograms of leaf grades of some parents, their $F_{1}$ 's and $F_{2}$ 's are shown in figs. 1-3. The near immunity of the American variety 101-102B (4), at all sites is striking (fig. I and table 2). It is demonstrably more resistant than is Bar 12/16 (6), a Sudan bred $B_{2} B_{2} B_{6} B_{6}$ type, which, nevertheless, maintained high resistance at all sites (fig. 2). The occurrence in some families of a point of minimum frequency in grade 1 is misleading: at the resistant end of the scale mechanical damage (e.g. insect punctures) can be mistaken for blight lesions. Grades 0,1 and 2 should perhaps be amalgamated, but Knight's (1946) scale has been retained for consistency.

Dominance of genes from 10l-102B is readily detectable in its progeny (fig. 1); the lack of susceptible segregants in the $F_{2}$ generation probably stems from segregation of the minor genes from Stoneville.

It was noted above that resistance attributed to the $B_{7}$ locus from Stoneville 20 was transferred to Acala 4.42 via G. barbadense to create Bar 24/5, 
and directly in breeding Acala 1517BR. Bird and Hadley (1958) emphasised that the Stoneville genes should be studied in more than one genetical background before making conclusions about dominance; their viewpoint is supported by present data and is of wider relevance than this instance.

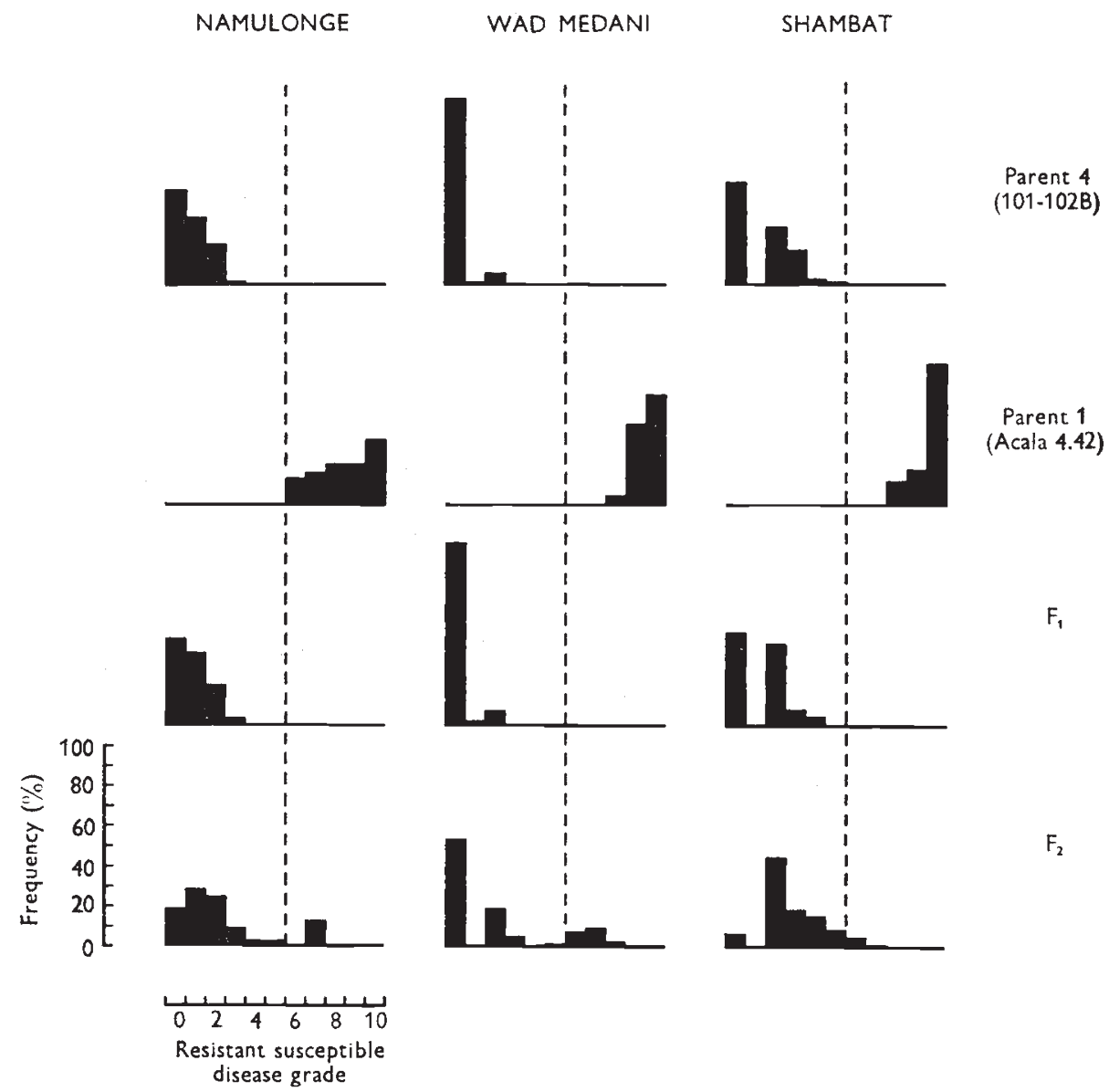

Frg. 1.-Leaf disease grades: percentage frequency histograms for $F_{1}$ and $F_{2}$ generations of 101-102B and Acala 4.42.

The resistance of Acala 1517BR is lower than that of Bar 24/5, the other variety containing $B_{7}$ (fig. 3 ). In $F_{1}$ and $F_{2}$ generations of Acala 1517BR $\times$ Acala $4.42(5 \times 1)$ most plants are susceptible; this is not so in equivalent populations of Bar $24 / 5 \times$ Acala $4.42(3 \times 1)$. The $F_{1}$ data suggest partial dominance of resistance and this is not contradicted in $\mathrm{F}_{2}$.

The evidence surprisingly fails to reveal a single gene of large effect. Possibly $B_{7}$ is a linked complex of genes, of low average dominance, prone to influence by genetical background. Alternatively, additional polygenic resistance may have been incorporated into Bar $24 / 5$ from the $G$. barbadense parent. If minor genes did participate they may have been true modifiers, undetectable in the absence of $B_{7}$. The strong influence of minor genes on the expression of $B_{7}$ is supported by the work of El-Zik and Bird (1970). 
(i) Leaf data

(b) Diallel analyses

Mean leaf grades given in tables 2 and 3 show that, on average, resistance in the hybrids is greater than the calculated mid-parental values. The

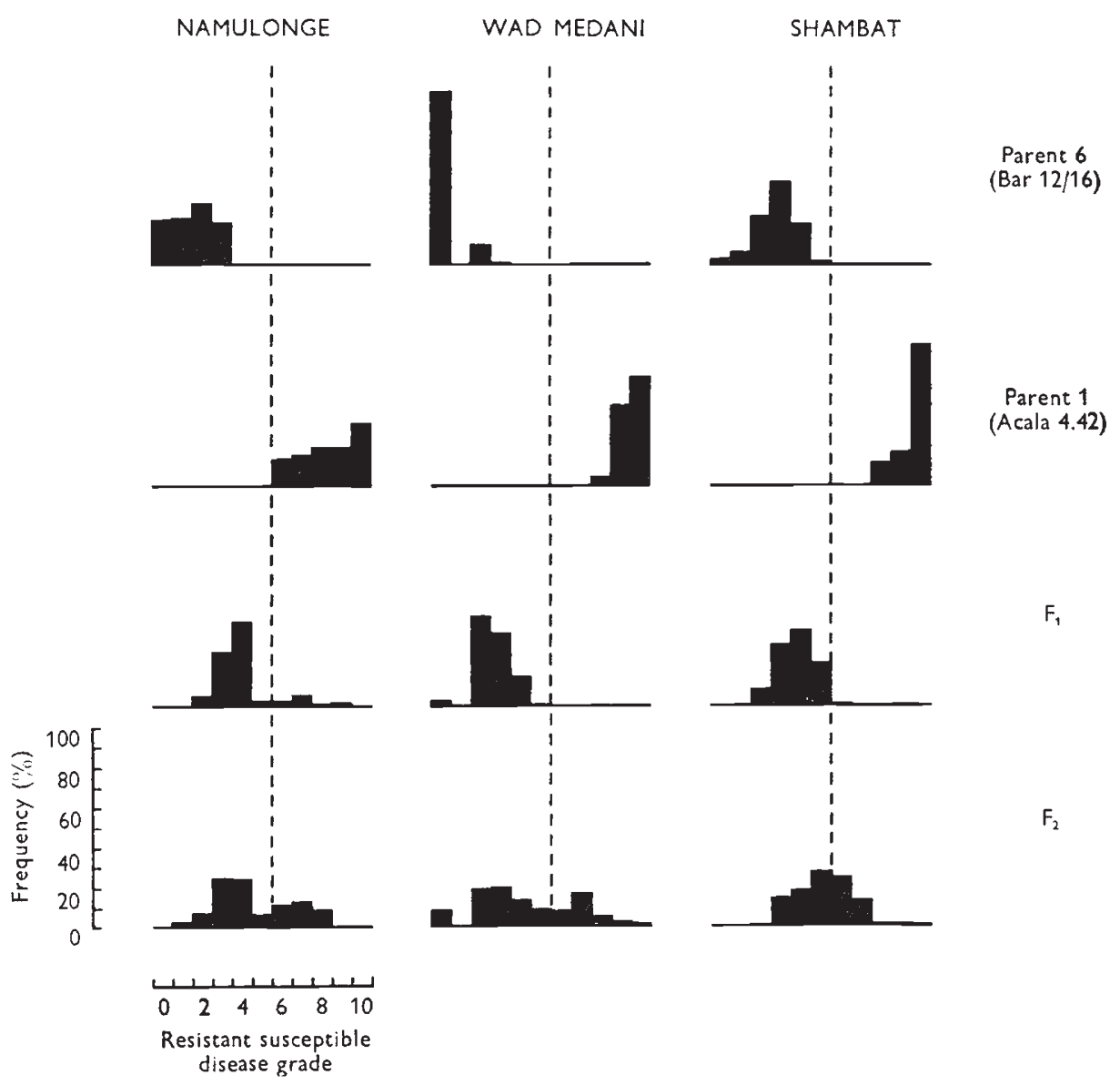

Fig. 2.-Leaf disease grades: percentage frequency histograms for $F_{1}$ and $F_{2}$ generations of Bar 12/16 and Acala 4.42.

overall potence is considerable, and much of what appears to be dominance variance is seemingly associated with parents 1 and 4 . The latter makes a particularly powerful contribution to resistance in hybrids.

Individual Hayman analyses of variance for $F_{1}$ and $F_{2}$ data at all sites concur in showing significant effects of additive and non-additive variance. Analysis of data combined over sites is shown in table 4.

The item designated $b_{1}$ is a measure of directional, non-additive effects, i.e. potence: in the absence of non-allelic interaction it is attributable to dominance. The $b_{3}$ term measures non-additive genetical variance ascribable to residual, specific interactions after accounting for parental array effects. Hayman considered that the $b_{2}$ item reveals asymmetry in gene distribution. 
The between sites main effect is significant $(P<0.05)$ for the $F_{1}$ generation only. Both $a$ and $b$ effects are strongly influenced by location, as shown by the relevant site interactions. Potence, however, is expressed largely independently of sites, as the sites $\times b_{1}$ interactions fail to reach significance in $\mathrm{F}_{1}$ and $\mathrm{F}_{2}$. On the other hand, both the $b_{2}$ and $b_{3}$ interactions with sites

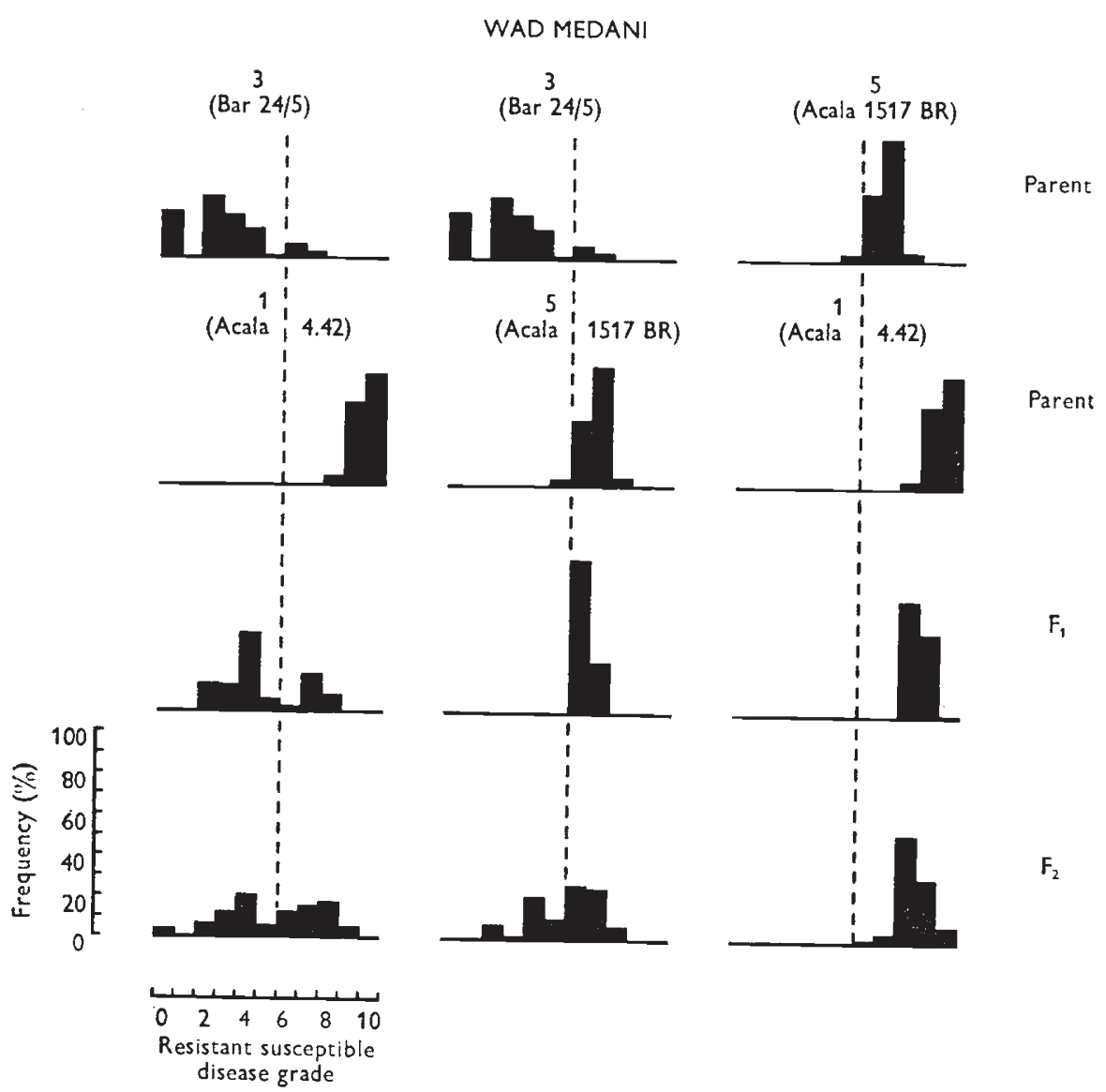

Fic. 3.-Leaf disease grades: percentage frequency histograms for $F_{1}$ and $F_{2}$ generations of Bar 24/5, Acala 1517BR and Acala 4.42.

are significant, indicating that environment influences the expression of the complex, non-additive effects.

As the Hayman analyses reveal non-additive effects we turn to the Jinks (1954) statistics to distinguish between dominance and non-allelic interaction. Regression lines in $W r / V r$ graphs (fig. 4) for both generations at all sites do not deviate significantly from unit slope. Non-allelic interaction is not therefore suspected, and the interceptions of the regression lines with the $\mathrm{Wr}$ axes indicate complete dominance after adjustment of the axes for error components. The strong dominance of 101-102B (4), shown in the histograms above, is re-emphasised here by the closeness of its array co-ordinate to the proximal intersection of regression line and limiting 
TABle 2

Mean leaf data for $F_{1}$ trials at Namulonge (top line), Wad Medani (second line) and Shambat (bottom line)

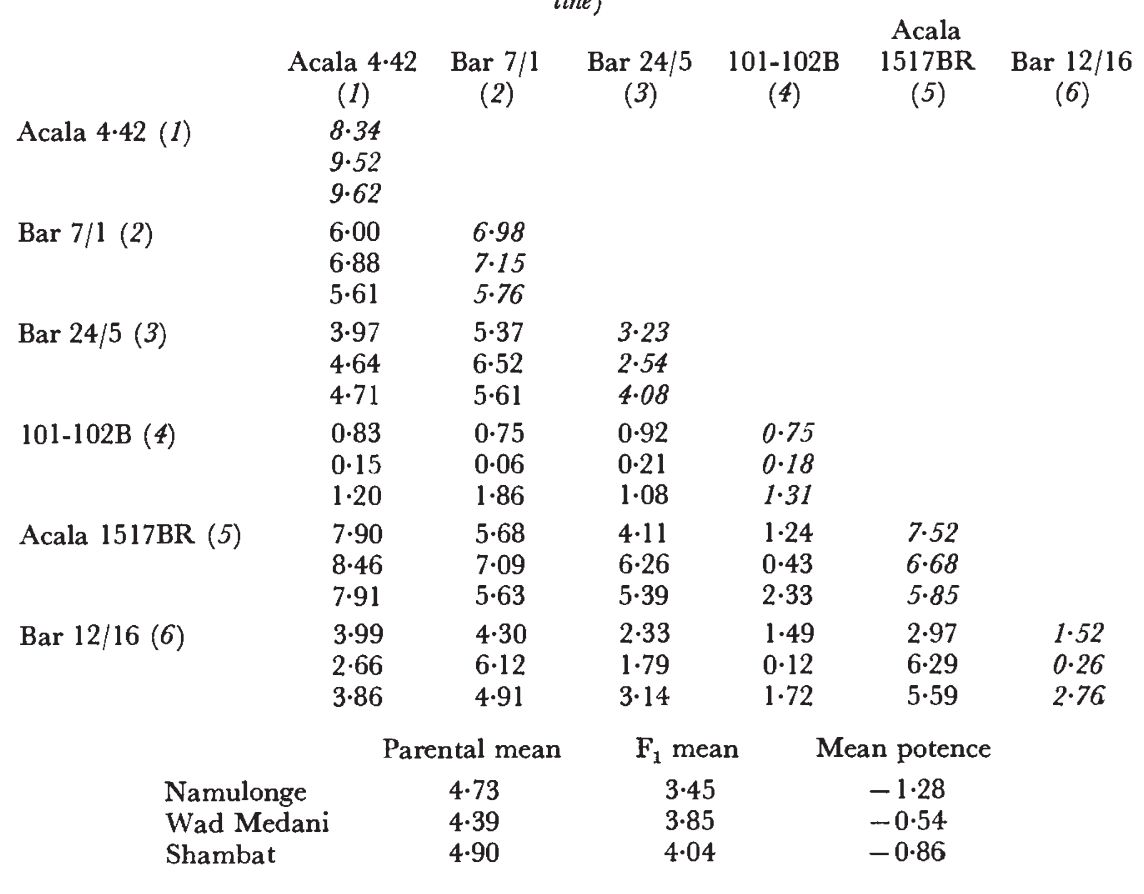

TABLE 3

Mean leaf data for $F_{2}$ trial at Namulonge (top line), Wad Medani (second line) and Shambat (bottom line)

Acala 4.42 Bar 7/1 Bar 24/5 101-102B 1517BR Bar 12/16
(I)
(2)
(3)
(4)
(5)
(6)

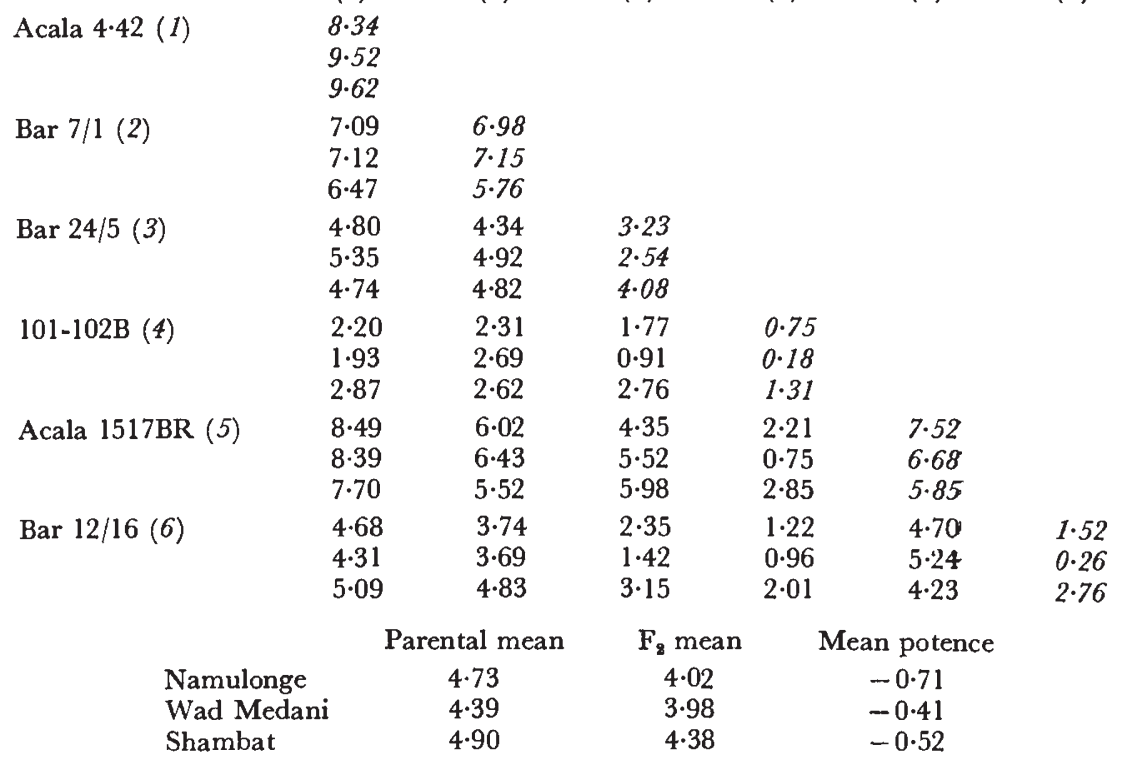


parabola. The Acala $4.42(1)$ array is consistently shown to contain mainly recessive alleles.

TABLE 4

Hayman analysis of variance: leaf disease grade over three sites

$a$

$b$

$b_{1}$
$b_{2}$
$b_{3}$
Sites $^{2}$

Sites

Blocks within sites

Sites $\times a$

Sites $\times b$

Sites $\times b_{1}$

Sites $\times b_{2}$

Sites $\times b_{3}$

Blocks within sites $\times a$

Blocks within sites $\times b$

Blocks within sites $\times b_{1}$

Blocks within sites $\times b_{2}$

Blocks within sites $\times b_{3}$

\begin{tabular}{|c|c|c|c|c|}
\hline \multicolumn{3}{|c|}{$F_{1}$} & \multicolumn{2}{|c|}{$F_{2}$} \\
\hline d.f. & M.S. & V.R. & M.S. & V.R. \\
\hline 5 & 208.952 & $154 \cdot 56 * * *$ & $188 \cdot 822$ & $171.97 * * *$ \\
\hline 15 & $14 \cdot 691$ & $22 \cdot 78 * * *$ & $5 \cdot 440$ & $12 \cdot 39 * *$ \\
\hline 1 & $30 \cdot 733$ & $44 \cdot 16 * * *$ & $11 \cdot 522$ & $41 \cdot 75^{* * *}$ \\
\hline 5 & $22 \cdot 472$ & $27 \cdot 30 * * *$ & $5 \cdot 862$ & $13 \cdot 89 * * *$ \\
\hline 9 & $8 \cdot 585$ & $15 \cdot 90 * * *$ & $4 \cdot 530$ & $9 \cdot 70 * * *$ \\
\hline 2 & $41 \cdot 778$ & $5 \cdot 24 *$ & $26 \cdot 545$ & 3.66 n.s. \\
\hline 6 & $7 \cdot 979$ & - & $7 \cdot 253$ & - \\
\hline 10 & 3.524 & $5 \cdot 61 * * *$ & $2 \cdot 994$ & $6 \cdot 42 * * *$ \\
\hline 30 & 1.577 & $4 \cdot 73 * * *$ & 0.772 & $2 \cdot 35^{* *}$ \\
\hline 2 & $1 \cdot 737$ & 4.98 n.s. & 0.287 & 1.05 n.s. \\
\hline 10 & $2 \cdot 421$ & $8 \cdot 34 * * *$ & 0.823 & $2 \cdot 86 * *$ \\
\hline 18 & $1 \cdot 091$ & $3 \cdot 07 * * *$ & 0.797 & $2 \cdot 24 *$ \\
\hline 30 & 0.628 & - & 0.466 & - \\
\hline 90 & 0.334 & - & 0.328 & - \\
\hline 6 & 0.349 & - & 0.272 & - \\
\hline 30 & $0 \cdot 290$ & - & $0 \cdot 288$ & - \\
\hline 54 & 0.356 & - & 0.357 & - \\
\hline
\end{tabular}

Further examination of these $W r / V r$ graphs reveals that co-ordinates of arrays 3 and 5 differ considerably at Namulonge but not at either Sudan site. Although both arrays contain the $B_{7}$ gene, the dominance relationships vary with environment.

This conclusion is confirmed by results of an Allard (1965a) type analysis of dominance and of genotype by environment interactions. Allard originally presented an amalgam of two different, but interrelated, analyses: the blight data herein are presented in separate form.

From table $5 a$ non-additive, genotypic differences between parents are shown to be significant by testing the arrays item against the arrays by sites interaction. This component detects differences in rank along the regression line, i.e. dominance in the absence of other non-additive contributions. The significance of the arrays by sites item against residual error from table $5 b$ indicates not only interaction of genotype with environment, but more specifically that non-additive variation is not constant. We shall see that parents do not maintain the same dominance relationships at three sites. Allard's test allows an estimate of the degree of dominance; the average dominance component is significant in an $\mathrm{F}_{\mathbf{1}}$ diallel when mean dominance is low or partial. The dominance item in table $5 b$ measures $\frac{1}{4}\left(D-H_{1}\right)$ in $\mathrm{F}_{1}$, therefore when $H / D=1$ dominance is complete and the term non-significant, as here. This corroborates the conclusion from the Jinks' $W r / V r$ analysis, where the close proximity of the intercept of the regression line to the origin also indicates complete dominance (fig. 4). In $F_{2}$ populations the item measures $\frac{1}{4}\left(D-\frac{1}{4} H_{1}\right)$, therefore even when dominance occurs significance is expected, and is indeed found here.

The dominance $x$ arrays item in each generation measures non-allelic interaction, correlated gene distribution, or both, among parents. The two 
F,

NAMULONGE
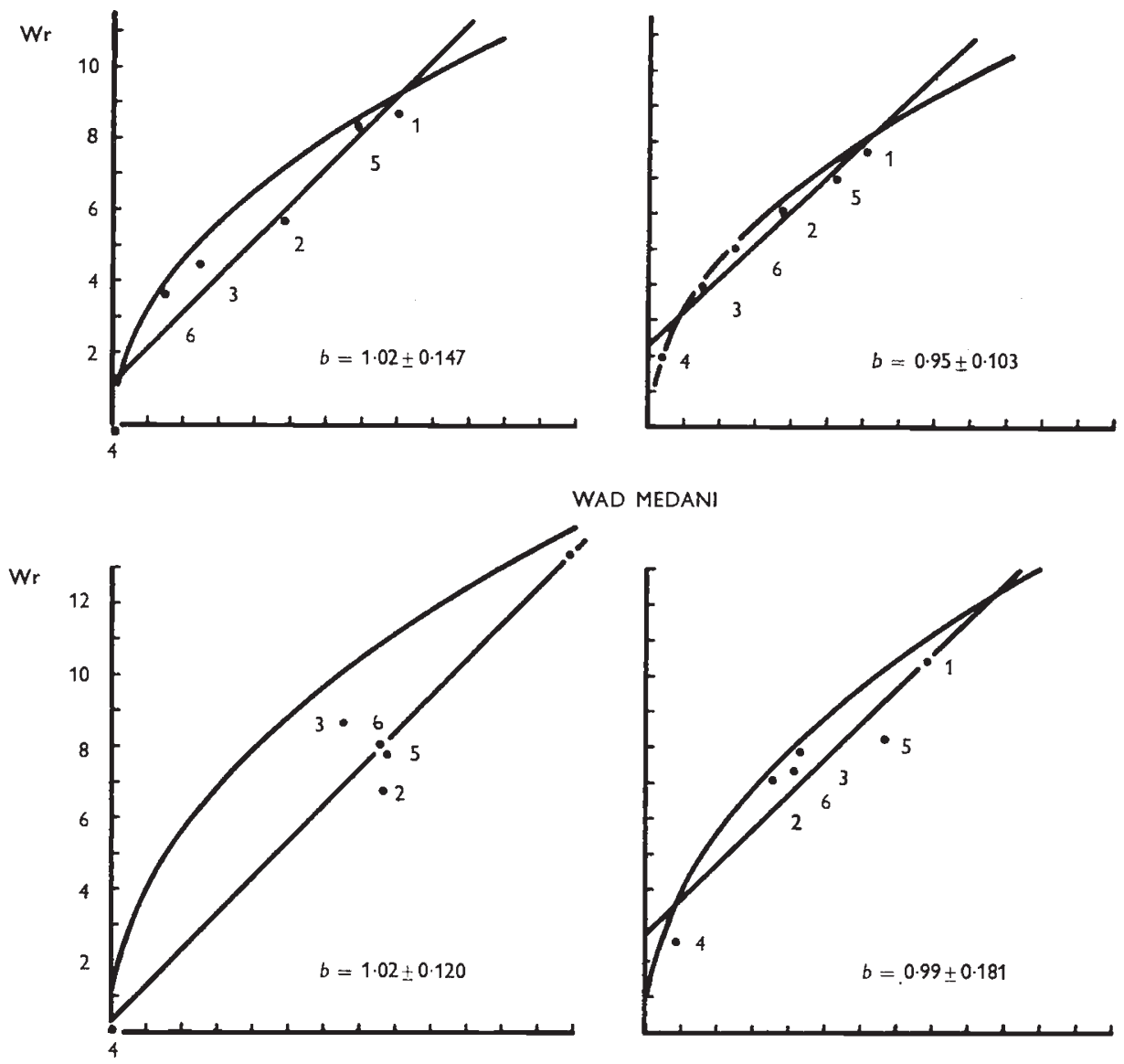

WAD MEDANI

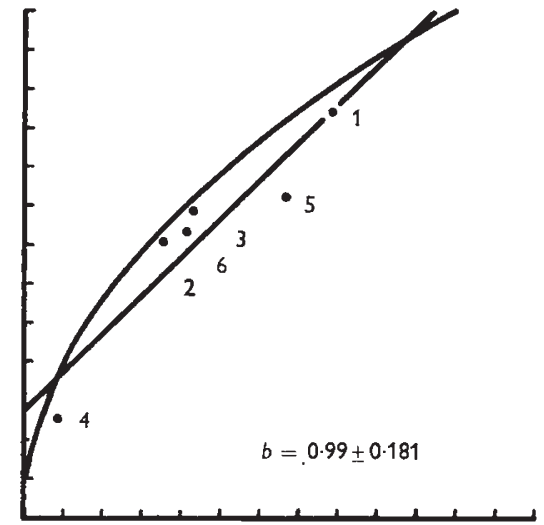

SHAMBAT
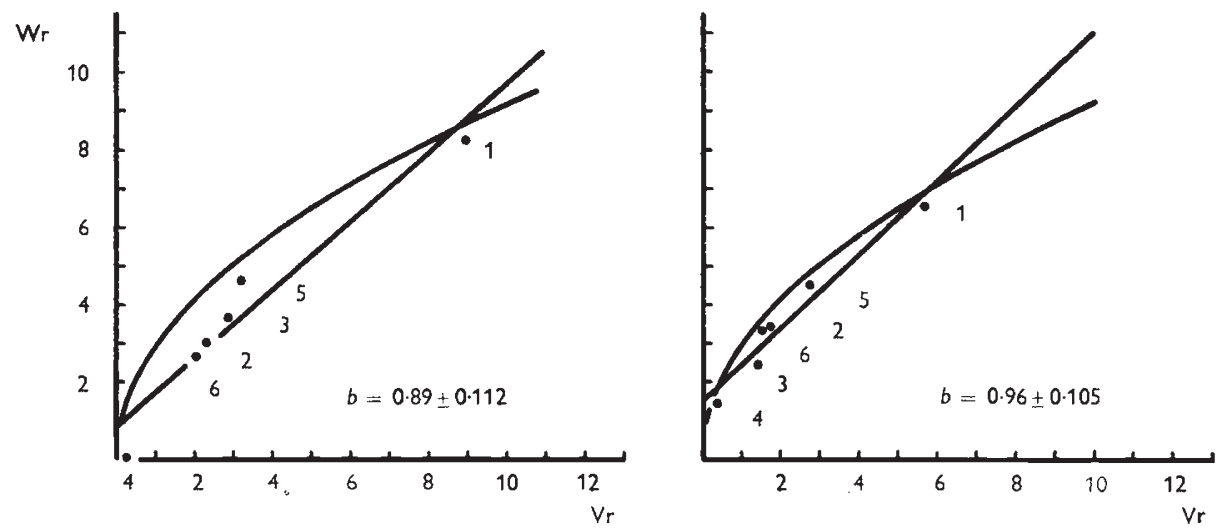

FIG. 4.-Leaf disease grades: the regression of array covariance $(W r)$ on array variance $(V r)$ at Namulonge, Wad Medani and Shambat. 1.-Acala 4.42;2.-Bar $7 / 1 ; 3 .-$ Bar 24/5; 4.-101-102B; 5.-Acala 1517BR; 6.-Bar 12/16. 
small, non-significant contributions allotted to this item indicate that dominance is the major source of non-additive variance. The variances for dominance $\times$ sites and the second order interaction (dominance $x$ arrays $\times$ sites), are specific measures of non-additive contributions, and in this case are non-significant.

TABLE $5 a$

Allard analysis for leaf data from three sites: array and site effects using $(\mathrm{Wr}+\mathrm{Vr})$ values

Arrays

Sites

Arrays $\times$ sites

\begin{tabular}{|c|c|c|c|c|}
\hline \multicolumn{3}{|c|}{$F_{1}$} & \multicolumn{2}{|r|}{$F_{2}$} \\
\hline d.f. & M.S. & V.R. & M.S. & V.R. \\
\hline $\begin{array}{r}5 \\
2 \\
10\end{array}$ & $\begin{array}{l}1.4635 \\
0.0112 \\
0.0964\end{array}$ & $\begin{array}{c}15 \cdot 18 * * * \\
<1 \\
(4 \cdot 55)^{* * * *}\end{array}$ & $\begin{array}{l}0.5822 \\
0.0125 \\
0.0250\end{array}$ & $\begin{array}{c}23.29 * * * \\
<1 \\
3.05^{* *}\end{array}$ \\
\hline
\end{tabular}

TABLE $5 b$

Allard analysis for leaf data from three sites: investigating dominance from $(\mathrm{Wr}-\mathrm{Vr})$ values

Dominance

Dominance $x$ arrays

Dominance $x$ sites

Dominance $\times$ arrays $\times$ sites

Error

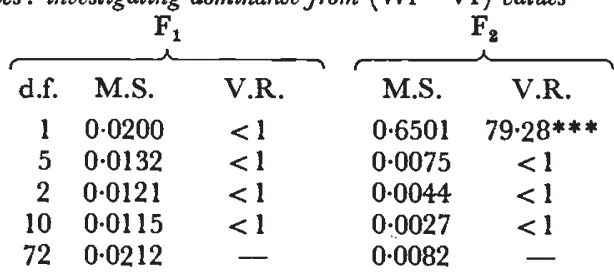

(ii) Boll data

Analyses of data with all arrays included. Mean values from transformed boll lesion scores are presented in tables 6 and 7 . In contrast to the leaf results, mean potence is not constant. For example, the hybrid scores indicate more resistance than the mean parental value using NCG 38 on occasion 1, whereas the reverse is true with the same culture on the other occasions.

Hayman analyses give very similar results for the three occasions when the same culture was used, so data for NCG 38 pooled over occasions are presented in table 8 . Additive genetic variance is again highly significant. The overall non-additive term $b$ is significant and there is evidence that the general and specific non-additive array effects, $b_{2}$ and $b_{3}$, are also significant. The situation differs from that obtaining for leaf scores in that there is no overall, directional, non-additive element here. We shall see below from the Jinks' analyses that non-allelic interaction is absent, so the present nonsignificance of $b_{1}$ presumably reflects the cancelling out of potence in two directions.

Results from Hayman analyses of data from boll lesions induced by cultures NCC 40 and NCC 38 inoculated on the same data are given in table 9. All genetic variances are smaller for NCC 40 than for NCC 38; in particular the non-additive genetical effects are relatively trivial. The bearing of this finding on experimentation with $X$. malvacearum is discussed below.

Turning to the Jinks' analysis to investigate non-additive genetic variance we find that the slopes of the six $W r / V r$ regression lines $\left(\mathrm{F}_{1}\right.$ and $\mathrm{F}_{2}$ for three occasions using NCC 38), do not differ significantly from unity. The nonadditivity can confidently be ascribed to dominance. Graphs for pooled data for $F_{1}$ and $F_{2}$ from the three occasions using NCC 38 are presented in 
fig. 5 , together with graphs relating separately to NCG 38 and NCC 40 on occasion 3.

On all graphs 101-102B (4) exhibits strong dominance. The difference in dominance between this and the other five parents is extreme using NCG 38 bacteria, array points along the NCG 40 regression line being more evenly

TABLE 6

Boll lesion data for $F_{1}$ at Namulonge. Top line: occasion 1, NCC 38. 2nd line: occasion 2, NCC 38. 3rd line: occasion 3, NCC 38. Bottom line: occasion 3, NCC 40

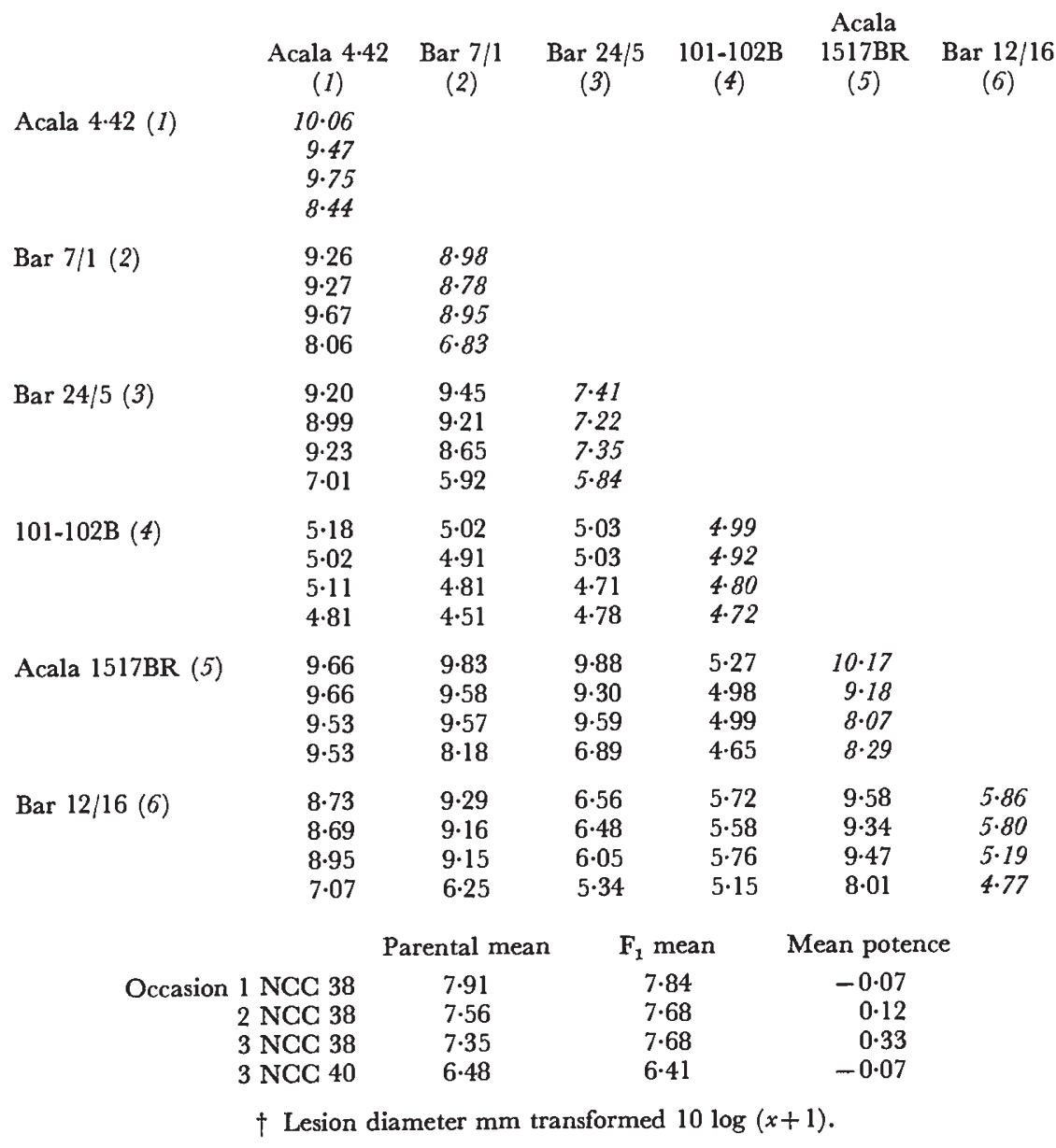

distributed. Where, as with the NCC $38 \mathrm{Wr} / \mathrm{Vr}$ graphs, there is striking discontinuity between groups of array points Allard (1956b) pointed out that in addition to indicating concentration of dominant alleles in one group the difference is probably governed by genetic units of comparatively large effect.

Results from an Allard-type analysis for three occasions with NCG 38 as infecting agent are given in table 10. From table $10 a$ large, non-additive genotypic differences are evident: differences due to occasions are significant only in the $\mathbf{F}_{\mathbf{1}}$ generation. The consistency of non-additive differences in 
boll lesion scores over occasions is shown by lack of significance of the arrays by occasions interaction. This contrasts with leaf scores over sites.

From table $10 b$ it seems that the average level of dominance for boll resistance is lower than that shown by the leaf data. This is shown by the significance of the dominance item in $F_{1}$ and its relatively low significance

TABLE 7

Boll lesion data $\dagger$ for $F_{2}$ at Namulonge. Top line: occasion 1, NCC 38. 2nd line: occasion 2, NCC 38 . 3rd line: occasion 3, NCC 38. Bottom line occasion 3, NCC 40

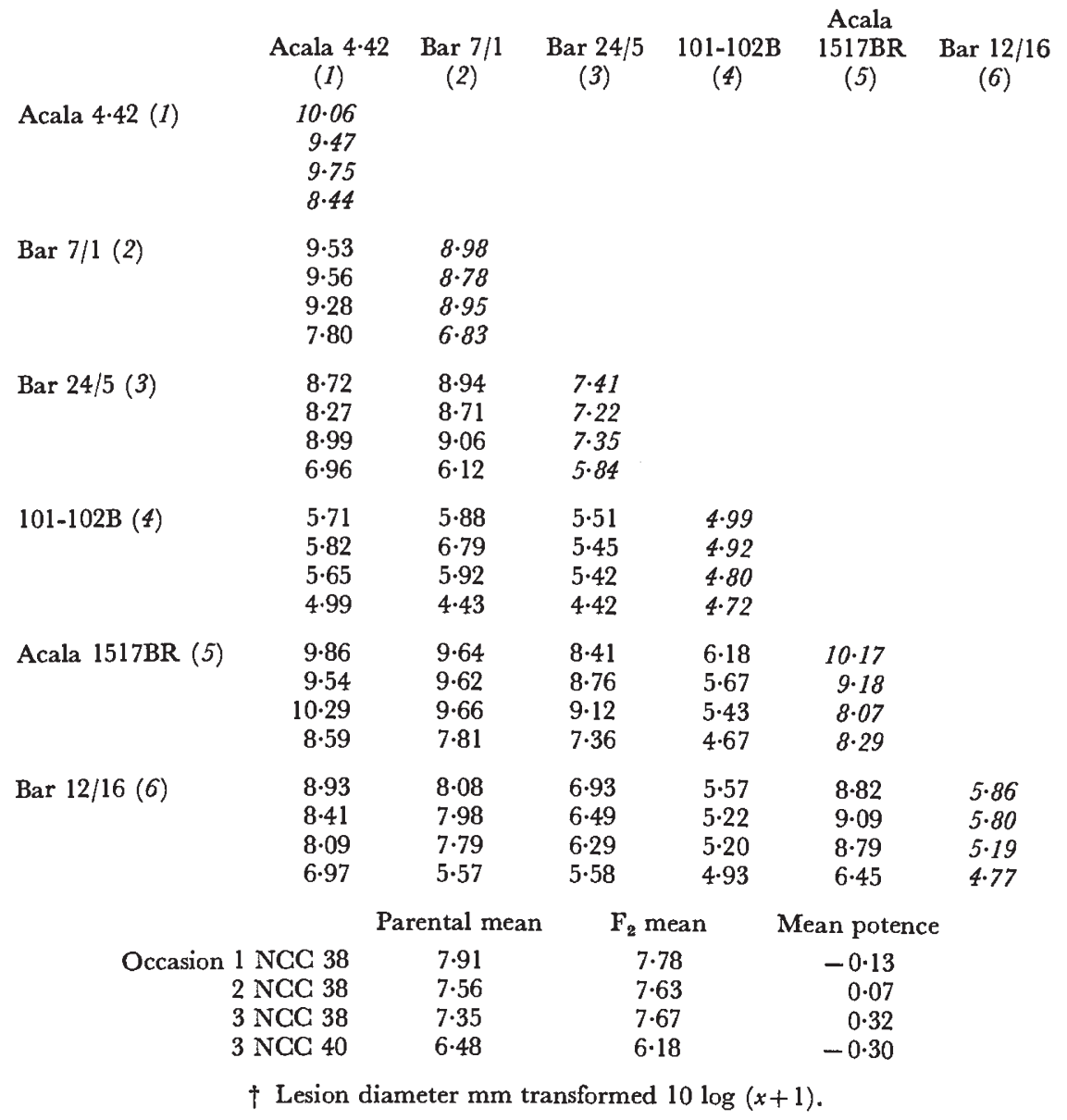

in $\mathbf{F}_{2}$. The dominance by arrays and dominance by occasions interactions are significant for $F_{1}$ but not for $F_{2}$, probably a direct consequence of the drop in average level of heterozygosity in the latter generation. The significance in $F_{1}$ of the dominance $\times$ arrays item is more likely to be due to correlated gene distribution than epistasis, as selected breeding material was used for parents. Another indicator of non-allelic interaction, the secondorder item, is non-significant, and the possibility of extensive epistasis occurring can be ruled out by the lack of significant deviation from unity in the slopes of the $W r / V r$ regression lines in fig. 5. 
Results of an Allard-type analysis of comparable NGG 38 and NGC 40 data are shown in tables $11 a$ and $11 b$, and once again non-additive genetical differences exist. It is noteworthy that the significant arrays $\times$ culture interactions show that relative dominance of the parents changes according to culture. This is also evident from the array co-ordinates in the $W r / V r$ graphs of fig. 5. The Allard dominance item in table $11 b$ is significant in

TABLE 8

Hayman analysis of variance: NCC 38 boll lesion data, all occasions, all arrays

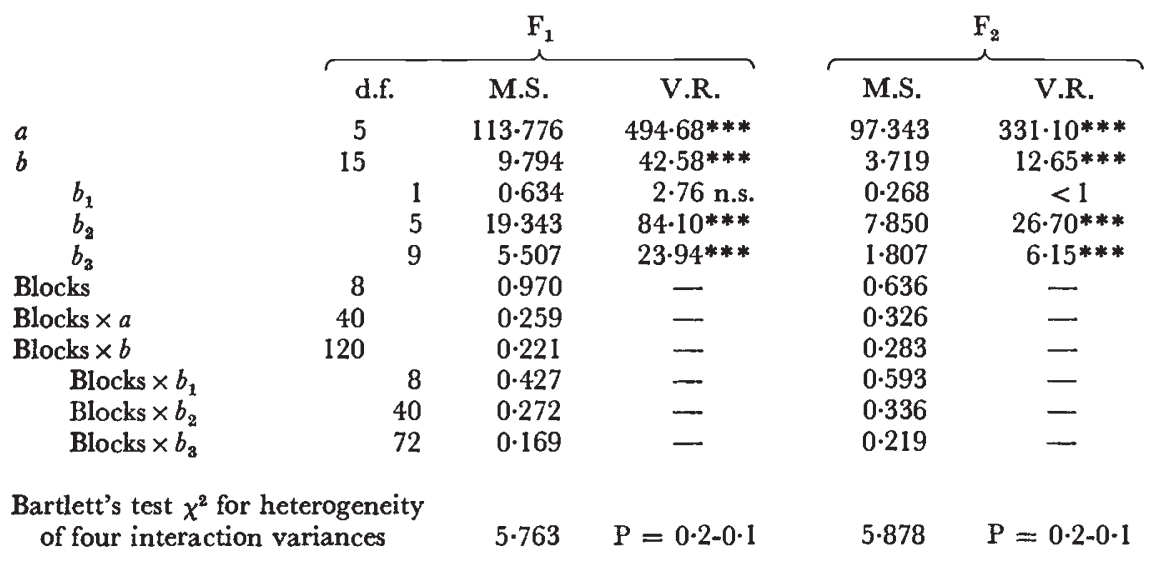

the $F_{1}$ and fails to reach significance in the $F_{2}$ so dominance is not complete, in sharp contrast with the leaf data analyses in table $5 b$. There is no indication of any epistasis.

Analysis of data with the 101-102 array omitted. The large, non-additive genetic variance conditioned by the inclusion of genotype 101-102B has clearly been demonstrated by Jinks and Allard tests to be due mainly to dominance. The boll data are of particular interest where they show a differential reaction of arrays to cultures, and these figures were re-analysed omitting 101-102B and its hybrids. There are no significant differences between the three occasions on which NGC 38 was used: analysis of results from NCC 38 and NGC 40 on occasion 3 are given in table 12.

Extensive non-additive genetic variance occurs in the populations lacking the 101-102B array and inoculated with NCG 38. This effect is strongly directional in $F_{1}$ and $F_{2}$, as witnessed by the high levels of significance of the $b_{1}$ terms. Despite the absence of array 4 we may conclude that dominant alleles are still present, as $W r / V r$ regression lines for NCC 38 data pooled over occasions have coefficients of $0.87 \pm 0.118$ and $0.91 \pm 0.092$ for $F_{1}$ and $\mathrm{F}_{2}$ data respectively.

On the other hand, deletion of the 101-102B array eliminates significant dominance variance when bacteria of the NGC 40 strain are used. In the absence of non-additive variation there is no point in undertaking Jinks' or Allard-type analyses.

\section{General discussion}

Interactions between the host cotton plant, the bacterial pathogen and the environment make it difficult to draw definite conclusions from studies 

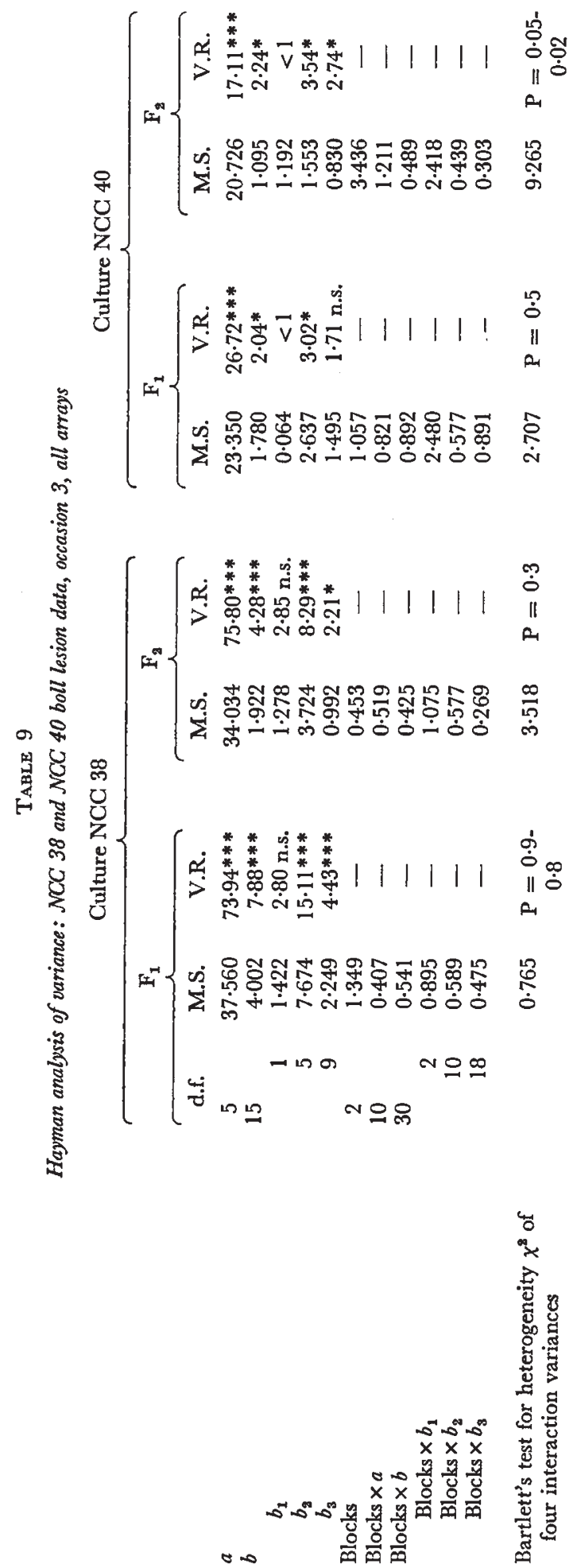
NAMULONGE

$F_{1}$

Three occasions pooled for culture NCC 38

Wr
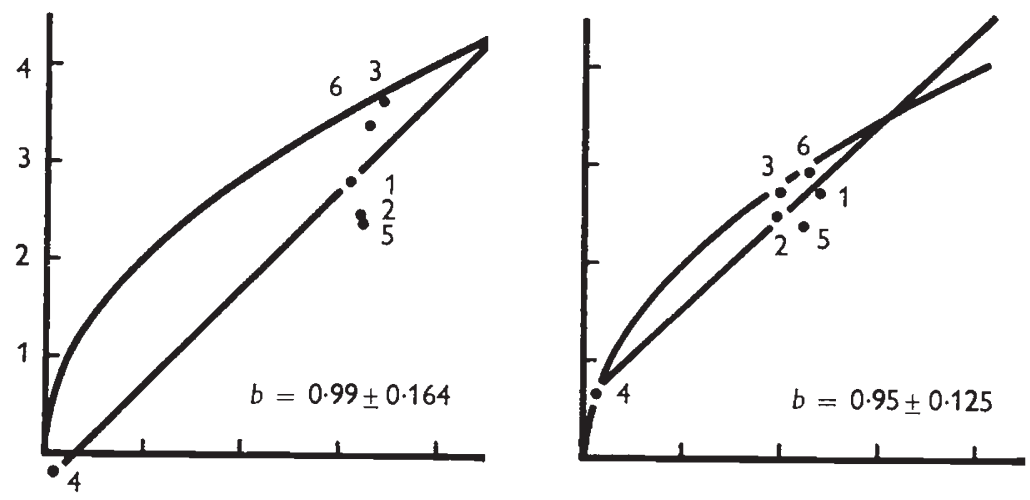

Occasion 3, culture NCC 38
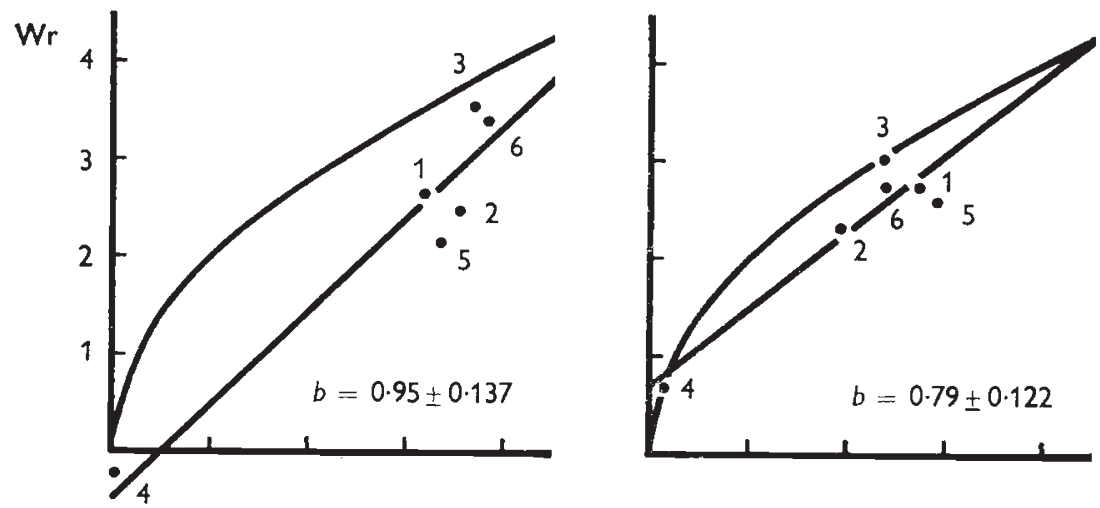

Occasion 3, culture NCC 40
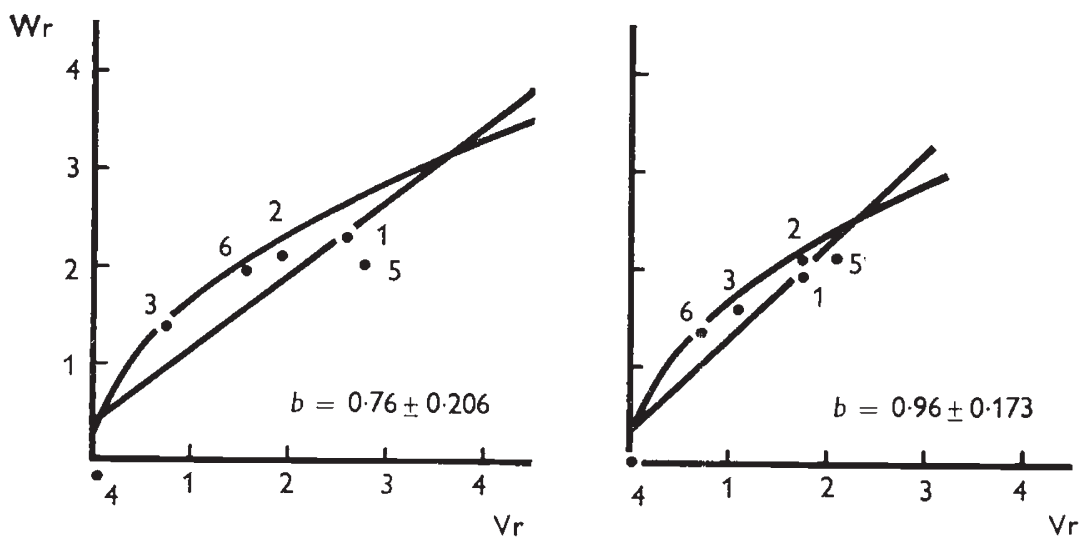

IG. 5.-Boll lesion data: the regression of array covariance $(W r)$ on array variance $(V r)$. Three occasions pooled for culture NCC 38; occasion 3, culture NCC 38 and occasion 3, culture NCC 40. 1.-Acala 4.42; 2.-Bar 7/1; 3.-Bar 24/5; 4.-101-102B; 5.-Acala 1517BR; 6. - Bar 12/16. 


\section{TABLE $10 a$}

Allard analysis for boll data using culture $\mathcal{N C C} 38$ : all arrays, three occasions, using

$(\mathrm{Wr}+\mathrm{Vr})$ values

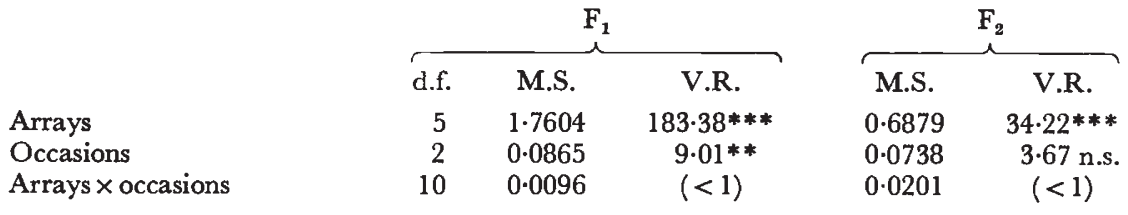

TABLE $10 b$

Allard analysis for boll data, using culture $\mathcal{N C C} 38$ : investigating dominance from $(\mathrm{Wr}-\mathrm{Vr})$ values

\begin{tabular}{|c|c|c|c|c|c|}
\hline & \multicolumn{3}{|c|}{$F_{1}$} & \multicolumn{2}{|c|}{$\mathrm{F}_{2}$} \\
\hline & d.f. & M.S. & V.R. & M.S. & V.R. \\
\hline Dominance & 1 & $0 \cdot 3191$ & $22 \cdot 31 * * *$ & $0 \cdot 1079$ & $4 \cdot 77 *$ \\
\hline Dominance $\times$ arrays & 5 & $0 \cdot 0468$ & $3 \cdot 27 * *$ & $0 \cdot 0152$ & $<1$ \\
\hline Dominance $\times$ occasions & 2 & $0 \cdot 0657$ & $4 \cdot 59 *$ & $0 \cdot 0331$ & 1.46 n.s. \\
\hline Dominance $\times$ arrays $\times$ occasions & 10 & 0.0023 & $<1$ & $0 \cdot 0023$ & $<1$ \\
\hline Error & 72 & $0 \cdot 0143$ & - & $0 \cdot 0226$ & - \\
\hline
\end{tabular}

TABLE $11 a$

Allard analysis for boll data: comparison of cultures $\mathcal{N C C} 38$ and NCC 40, using all arrays and $(\mathrm{Wr}+\mathrm{Vr})$ values

\begin{tabular}{|c|c|c|c|c|c|}
\hline & & $F_{1}$ & & & \\
\hline & d.f. & M.S. & V.R. & M.S. & V.R. \\
\hline Arrays & 5 & $1 \cdot 2116$ & $6 \cdot 39 *$ & 0.7498 & $6 \cdot 04 *$ \\
\hline Cultures & 1 & 0.0103 & $<1$ & $0 \cdot 0006$ & $<1$ \\
\hline Arrays $\times$ cultures & 5 & $0 \cdot 1896$ & $3 \cdot 08 *$ & 0.1242 & $2 \cdot 75 *$ \\
\hline
\end{tabular}

TABLE $11 b$

Allard analysis for boll data: comparison of cultures, investigating dominance from $(\mathrm{Wr}-\mathrm{Vr})$ values

Dominance

Dominance $x$ arrays

Dominance $x$ cultures

Dominance $x$ arrays $\times$ cultures

Error

\begin{tabular}{|c|c|c|}
\hline d.f. & M.S. & V.R. \\
\hline 1 & 0.7327 & $11 \cdot 91 * *$ \\
\hline 5 & 0.0575 & $<1$ \\
\hline 1 & 0.0005 & $<1$ \\
\hline 5 & 0.0078 & $<1$ \\
\hline 48 & 0.0615 & - \\
\hline
\end{tabular}

of resistance to blight. Experimentation with a range of host and parasite genotypes, brought together under different environmental conditions, reveals some of the implications of drawing conclusions about genetic control from measuring lesions of infected plants.

Arnold (1963) and Arnold and Brown (1968) must be credited with 


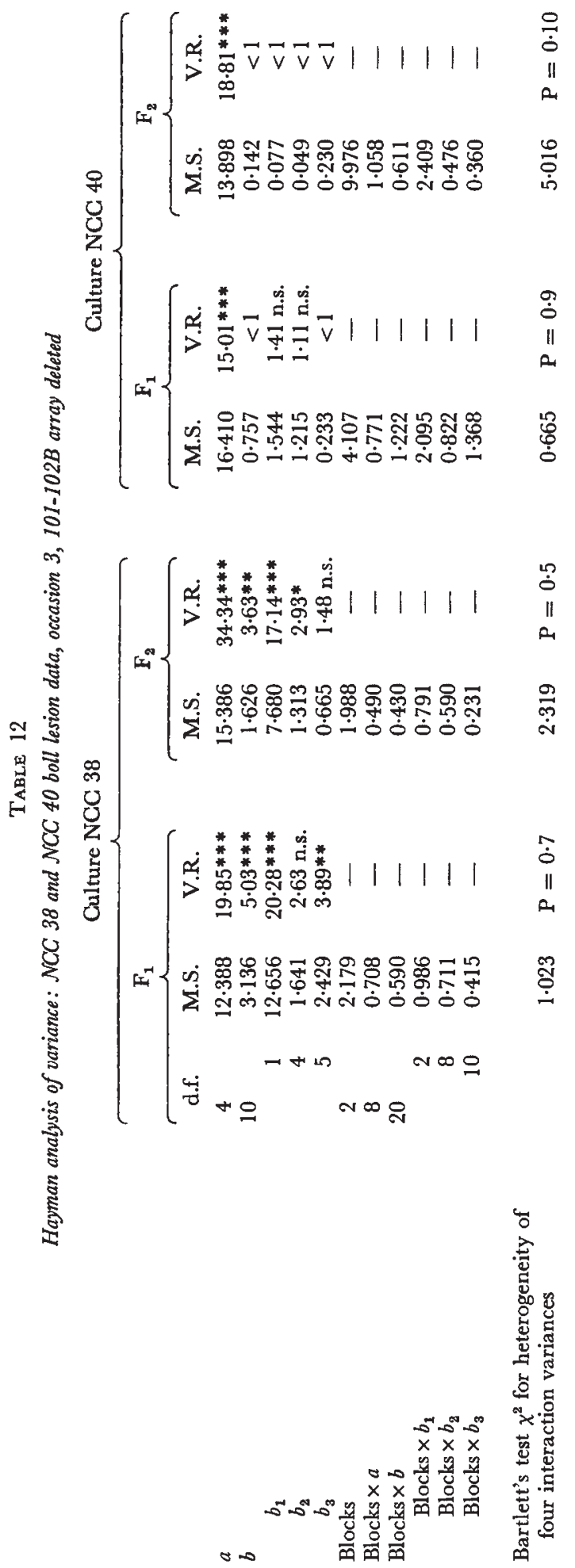


stimulating interest in the three-way interactions. They stressed the interdependence of the factors which influence the host-parasite relationships: any one factor can only be studied effectively over a range of variation in the others. In the foreseeable future it is unlikely that sufficient phytotron facilities will be available for testing the large populations required for this type of study using mature cotton plants, and one cannot extrapolate from seedling cotyledons to fruits. Field experimentation is therefore required to complement the limited results obtainable from artificial control of the environment. Attempts at studying resistance to two bacterial strains under widely differing field conditions by the use of diallel crosses are described.

Of the three statistical methods of diallel analysis employed, Hayman's (1954a) method was used first to detect and evaluate non-additive genetic variance. The $W r / V r$ graphs in the Jinks analysis were subsequently of most use in differentiating between dominance and epistasis, and for indicating the distribution of dominant and recessive alleles in the inbred lines. Such graphs, and the Allard-type (1956a) analysis, were also useful in revealing changes in the relative dominance of alleles in the parents, as in the case when the two bacterial cultures were compared.

Parent 4 , the line $101-102 \mathrm{~B}$, is the major source of interest. It was derived from a cross of the American variety Empire WR (G. hirsutum) and Bar 4/16, a Sudan $G$. barbadense line containing Knight's (1957) $B_{2} B_{3}$ genes. Five backcrosses to Empire were followed by one to the blight susceptible selection MVW (L. S. Bird, personal communication). Empire WR, a selection from Stoneville, has little blight resistance but contains the $B_{S m}$ minor gene complex (El-Zik and Bird, 1970). No other known $B_{2} B_{2} B_{3} B_{3}$ cotton possesses resistance at a level approaching that shown by 101-102B. The variety is virtually immune in the U.S.A. (Hunter, Brinkerhoff and Bird, 1968) and in India (Verma and Singh, 1970).

The strong effectiveness and dominance of the genes in 101-102B has been demonstrated, and there are several implications.

Firstly, 101-102B represents a powerful source of resistance to two representative, highly virulent bacterial cultures. Under the conditions in which this genotype has so far been tested it is nearly immune. Whereas all cotton growing conditions have not been represented, 101-102B could presumably contribute to the synthesis of varieties with outstanding resistance.

Secondly the performance of 101-102B is remarkable in that part of the resistance is supposedly polygenic (the $B_{S m}$ complex). The variety may contain major resistance genes other than $B_{2} B_{3}$ and $B_{S m}$, though it is difficult to see where any other known loci could have been used in its breeding. It may be that in the presence of $B_{2} B_{3}$, the $B_{S_{m}}$ complex acts as a modifier, similar in action to Knight's $B_{6}$. It is also possible that a modifier gene, capable of interacting with the $B_{2}$ and $B_{3}$ loci, could have been in MVW, but this is less likely. In a study involving Knight's $B_{4}, B_{7}$ and the combinations $B_{2} B_{3}, B_{2} B_{3} B_{7}$ and $B_{2} B_{6}$ transferred to different varietal backgrounds, El-Zik and Bird (1970) found that Empire WR, with its $B_{S m}$ complex, was most effective in boosting major gene resistance. The $B_{S m}$ complex from Deltapine TPSA was more effective than $B_{T m}$ from Texacala.

Whilst studying the highly effective resistance in Arnold's (1963) UKBR African Upland lines selected in Tanzania Innes (1969) found that these contained a polygene complex which increased the basic resistance conferred by the major gene $B_{2}$. The UKBR lines were obtained by progressive 
exploitation of residual genetic variability by selection during pedigree line breeding. Innes therefore postulated that polygenes had been built into an effective block which simulated the behaviour of a major gene.

There is now evidence to suggest that a stable supergene has been synthesised in 101-102B, and analyses presented above suggest that it is dominant in action. The overall level of non-additive variability is strongly affected by the inclusion or exclusion of the 101-102B array from the analyses. The inclusion of a genotype which so markedly extends the dominance range of a set of diallel parents can have disturbing effects on biometrical studies. The estimation of genetical parameters would be different in a diallel set with regular incremental differences in dominance.

The bacterial cultures NCC 38 and NCC 40 have been shown to behave differently in this study, and there are many other genotypes of $X$. malvacearum (e.g. Brinkerhoff, 1963; Arnold and Brown, 1968). Where naturally infected trash is used as a source of inoculum (e.g. Knight, 1946) a wide range of genotypes probably occurs. At Namulonge, mixtures of cultures are used in breeding programmes. Each component is tested separately to assess its virulence, and mixtures of cultures are checked to ensure that combinations in which components are antagonistic (Brown, 1966) are not used.

There has been controversy as to whether, in cotton, seedling and adult plant resistance to blight are related (see Arnold, 1963; Innes, 1966). Arnold pointed out the need for care in interpretation because of interactions of genotype with environment. When considering, for example, the relationship between resistance in leaves and bolls on the same plant inoculated at different times even with the same bacterial strain the infected organs are subjected to different conditions. He concluded from his own results that a basic mechanism controlled leaf, stem and boll resistance to $X$. malvacearum, but that additional factors probably operated in certain tissues, such as stems.

Innes (1966) found evidence of genetic differences in certain genotypes when leaf and stem resistance were evaluated, but whatever the cause of such variation between organs and at different physiological ages, the present results reinforce the conclusions of Arnold and Brown (1968). They insisted that in breeding cotton it is desirable to screen for resistance at different stages of plant growth and in a range of environments. Programmes based on alternate testing sites are more likely to produce plants with wellbalanced resistance mechanisms than are those in which genotypes evolve in isolation.

Acknowledgments.-Mr J. H. Saunders and Sayed A. I. Kheiralla kindly supervised scoring in the Sudan trials, data from which are published by permission of the Director, Sudan Agricultural Research Corporation. We are indebted to Dr M. H. Arnold and Professors J. M. Thoday and R. W. Allard for reading the typescript, and Dr M. J. Lawrence for comments on interpretation.

\section{References}

Allard, R. W. 1956a. The analysis of genetic-environment interactions by means of diallel crosses. Genetics, 41, 305-318.

Allard, R. w. 1956b. Estimation of prepotency from Lima bean diallel cross data. Agron. J., 48, 537-543.

ARNOLD, M. H. 1963. The control of bacterial blight in raingrown cotton. 1. Breeding for resistance in African Upland varieties. 7. agric. Sci. Camb., 60, 415-427. 
ARNOLD, M. H., AND BROWN, s. J. 1968. Variation in the host-parasite relationship of a crop disease. 7. agric. Sci. Camb., 71, 19-36.

BIRD, L. S., AND HADLEY, H. H. 1958. A statistical study of the inheritance of Stoneville 20 resistance to the bacterial blight disease of cotton in the presence of Xanthomonas malvacearum races 1 and 2 . Genetics, 43, 750-767.

BLANK, L. M., AND HUNTER, R. E. 1955. 1517BR. A blight-resistant strain of Acala cotton. New Mexico College of Agriculture and Mechanic Arts. Agric. Exp. Sta. Press Bulletin, 1132.

BRINKERHOFF, L. A. 1963. Variability of Xanthomonas malvacearum: the cotton bacterial blight pathogen. Oklahoma State University Technical Bulletin, T-98.

Brown, s. J. 1966. Prog. Rep. Exp. Stas., Rep. Cott. Gr. Corp. 1964-65, Uganda, p. 23.

EL-ZIK, K. M., AND BIRD, L. s. 1970. Effectiveness of specific genes and gene combinations in conferring resistance to races of Xanthomonas malvacearum in Upland cotton. Phytopath., $60,441-447$.

hayman, B. I. 1954a. The analysis of variance of diallel tables. Biometrics, 10, 235-244.

Hayman, B. I. 1954b. The theory and analysis of diallel crosses. Genetics, 39, 789-809.

HUNTER, R. E., BRINkERHOFF, L. A., AND BIRD, L. S. 1968. The development of a set of Upland cotton lines for differentiating races of Xanthomonas malvacearum. Phytopath., 58, 830-832.

INNES, N. L. 1964. Sudan strains of cotton resistant to bacterial blight. Emp. Cott. Gr. Rev., $41,285-291$.

INNES, N. L. 1966. Inheritance of resistance to bacterial blight of cotton. 3. Herbaceum resistance transferred to tetraploid cotton. F. agric. Sci., Camb., 66, 433-439.

INNES, N. L. 1969. Inheritance of resistance to bacterial blight of cotton. IV. Tanzania selections. F. agric. Sci., Camb., 72, 41-57.

INNES, N. L. 1970. Breeding for bacterial blight resistance. In Cotton Growth in the Gezira Environment, Ed. M. A. Siddig and L. C. Hughes. Sudan Agricultural Research Corporation.

INNES, N. L., AND BROWN, s. J. 1969. A quantitative study of the inheritance of resistance to bacterial blight in Upland cotton. F. agric. Sci., Camb., 73, 15-23.

JINKs, J. L. 1954. The analysis of continuous variation in a diallel cross of Nicotiana rustica varieties. Genetics, 39, 767-788.

JOHAM, H. E., LIPKE, W. G., AND HOLD, G. 1967. An association of free and peptide amino compounds of leaves with resistance of cotton to Xanthomonas malvacearum (E. F. Sm.) Dowson. Proceedings of Beltwide Cotton Production Research Conferences. Jan. 10-11, 217-220.

KNIGHT, R. L. 1946. Breeding cotton resistant to blackarm disease. Part II. Breeding methods. Emp. 7. exp. Agric., 14, 161-74.

KNIGHT, R. L. 1957. Blackarm disease of cotton and its control. Plant Protection Conf. 1956, p. 53. Butterworth, London.

KNIGHT, R. L. 1963. The genetics of blackarm resistance. 12. Transference of resistance from Gossypium herbaceum to G. barbadense. 7. Genet., 58, 328-346.

KNIGHT, R. L., AND ClOUSTON, T. W. 1939. The genetics of blackarm resistance. 1. Factors $B_{1}$ and $B_{2}$. F. Genet., 38, 133-159.

SAUNDERS, J. H., AND INNES, N. L. 1963. The genetics of bacterial blight resistance in cotton. Further evidence on the gene $B_{6}$. Genet. Res., Camb., 4, 382-388.

VERMA, J. P., AND SINGH, R. P. 1970. Two new races of Xanthomonas malvacearum, the cause of blackarm of cotton. Cott. Gr. Rev., 47, 203-205. 